\title{
Commentary: Axillary artery cannulation was used safely for the stable majority of patients
}

\author{
Tohru Asai, MD, PhD
}

From the Division of Cardiovascular Surgery, Shiga University of Medical Science, Otsu, Japan

Disclosures: Author has nothing to disclose with regard to commercial support.

Received for publication Dec 11, 2018; accepted for publication Dec 11, 2018; available ahead of print Jan 17, 2019.

Address for reprints: Tohru Asai, MD, PhD, Division of Cardiovascular Surgery, Shiga University of Medical

Science, Seta Tsukinowacho, Otsu, Shiga 520-2192, Japan (E-mail: toruasai@belle.shiga-med.ac.jp).

J Thorac Cardiovasc Surg 2019;158:664

$0022-5223 / \$ 36.00$

Copyright (c) 2018 by The American Association for Thoracic Surgery

https://doi.org/10.1016/j.jtcvs.2018.12.032

Acute type A aortic dissection is a life-threatening condition requiring emergency surgical repair. ${ }^{1}$ However, choice of arterial cannulation site is a matter of debate, for several reasons. Acute type A dissections vary in extent and in extensions into branch arteries. Complications include preoperative and iatrogenic organ malperfusion, and hemodynamic instability may constrain treatment options. The choice of arterial cannulation site may also be influenced by surgeon preference. Further, surgical procedures vary from a simple ascending aortic replacement to aortic root reconstruction procedures and/or even extensive aortic arch repair with individual branch reconstruction.

Rosinsky and colleagues ${ }^{2}$ present data reviewing their large center's experience of systematic initial axillary artery cannulation for acute type A dissection repair. This approach was used for $80 \%$ of 775 patients, and the cannulation site was shifted intraoperatively in only $3.7 \%$ of that group. In-hospital mortality was $8.6 \%$ for those 775 patients, and $7.6 \%$ for the axillary cannulation group, which was the lowest among the different cannulation groups. They conclude that their initial axillary artery cannulation approach was feasible and safe in the majority of patients.

Various cannulation strategies have been used for acute type A dissection repair. There has been a trend away from femoral artery cannulation toward use of the axillary artery, right brachiocephalic artery, ascending aorta, ${ }^{3}$ and left ventricle. Each approach has its advantages and limitations. Axillary artery cannulation has recently gained in popularity partly for its advantages in proximal and mostly antegrade aortic perfusion during cardiopulmonary bypass, and in facilitating cerebral perfusion during hypothermic circulatory arrest. This approach also has limitations, for at least 2 reasons. First, axillary artery cannulation is cumbersome and too time-consuming for an emergency condition with hemodynamic instability. Second, special care is needed to avoid possible local complications with the axillary artery, especially in patients with very fragile tissues.

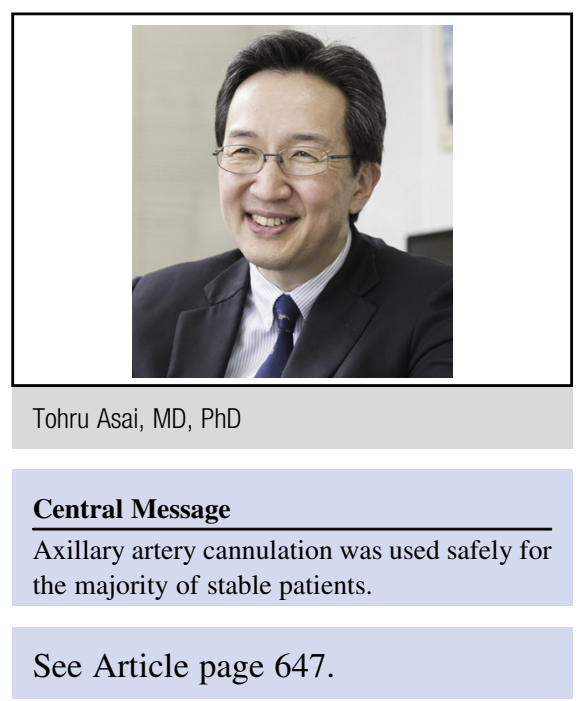

Rosinsky and colleagues ${ }^{2}$ show that their initial axillary artery cannulation approach was safely applicable for most acute type A dissection repair cases, especially in patients with stable hemodynamic parameters and in an evidently large-volume center; the need for additional cannulation shift was rare. However, as they state, because axillary cannulation was their preferred method, the comparison between the different cannulation strategies has obvious biases and needs to be interpreted carefully. Further investigation comparing cannulation sites will be needed in multicenter prospective studies to account for factors such as preoperative organ malperfusion, malperfusion arising during cardiopulmonary bypass, management of temperature, duration of circulatory arrest, and types and extents of surgical repair. No single approach would be optimal in all cases, but Rosinsky and colleagues ${ }^{2}$ have provided some very good and interesting data.

\section{References}

1. Lee TC, Kon Z, Cheema FH, Grau-Sepulveda MV, Englum B, Kim S, et al. Contemporary management and outcomes of acute type A aortic dissection: an analysis of the STS Adult Cardiac Surgery database. J Card Surg. 2018;33:7-18.

2. Rosinski BF, Idrees JJ, Roselli EE, Germano E, Pasadyn SR, Lowry AM, et al. Cannulation strategies in acute type A dissection repair: a systematic axillary artery approach. J Thorac Cardiovasc Surg. 2019;158:647-59.e5.

3. Frederick JR, Yang E, Trubelja A, Desai ND, Szeto WY, Pochettino A, et al. Ascending aortic cannulation in acute type a dissection repair. Ann Thorac Surg. 2013;95:1808-11. 